\title{
Performance Analysis of a Direct Carbon Fuel Cell Cogeneration System Combined with a Two-Stage Thermoelectric Generator
}

\author{
Jiahui Liu ${ }^{1}$, Houcheng Zhang ${ }^{\text {1,* , Jiatang Wang }}{ }^{2}$, Jiapei Zhao ${ }^{2}, \mathrm{Fu} \mathrm{Wang}^{2}$, He Miao ${ }^{2}$, \\ Jinliang Yuan', Shujin Hou ${ }^{3, *}$ \\ ${ }^{1}$ Department of Microelectronic Science and Engineering, Ningbo University, Ningbo 315211, China \\ ${ }^{2}$ Faculty of Maritime and Transportation, Ningbo University, Ningbo 315211, China \\ ${ }^{3}$ College of Physics and Electronic Engineering, Nanyang Normal University, Nanyang 473061, \\ China \\ *E-mail: zhanghoucheng@ nbu.edu.cn (H. Zhang), houshujingrb@163.com (S. Hou).
}

doi: $10.20964 / 2019.04 .32$

Received: 2 December 2018 / Accepted: 25 January 2019 / Published: 10 March 2019

\begin{abstract}
A new cogeneration system model consisting of a DCFC (direct carbon fuel cell), a TTEG (two-stage thermoelectric generator) and a regenerator is proposed, where the DCFC directly and efficiently converts the chemical energy of carbon into electricity and waste heat, and the TTEG harvests the waste heat for additional electricity production. For a given heat flow rate, the TTEG is optimized using maximum power output as an objective function. An analytic relationship between the operating current density of DCFC and the dimensionless electric current of optimized TTEG is derived. The mathematical formulas for the power output and efficiency of the cogeneration system are specified under different operating conditions. The proposed hybrid system is found to be more efficient than the sole DCFC and DCFC-TEG hybrid system. It is found that the maximum attainable power density allows about $50 \%$ larger than that of the stand-alone DCFC. Furthermore, the effects of operating current density, operating temperature, heat conductivity, number of thermocouples, figure of merit of the thermoelectric materials and DCFC anode dimension on the cogeneration system performance are discussed in detail.
\end{abstract}

Keywords: Direct carbon fuel cell; Two-stage thermoelectric generator; Cogeneration system; Performance analysis; Parametric study

\section{FULL TEXT}

(C) 2019 The Authors. Published by ESG (www.electrochemsci.org). This article is an open access article distributed under the terms and conditions of the Creative Commons Attribution license (http://creativecommons.org/licenses/by/4.0/). 